\title{
Analysis of the Technico-Economic Viability of an Electric Micro-Grid with Renewable Electricity Production Sources in Elokato-Bingerville, Cote d'Ivoire
}

\author{
Toure Minayégnan ${ }^{*}$, Oyedele Sampson Oladapo ${ }^{2,3}$, Koita M. Sako ${ }^{1}$, Christophe Marvillet ${ }^{4}$, \\ Christophe Marvillet ${ }^{4}$
}

${ }^{1}$ UMRI 58, Laboratory of Industrial Synthesis, Environment and New Energies (LAPISEN), INP-HB, Yamoussoukro, Côte d'Ivoire ${ }^{2}$ Science Fondamentale Appliquée, Universite Nangui Abrogoua, Abidjan, Côte d'Ivoire ${ }^{3}$ Institut de Recherche en Energie Nouvelle, Universite Nangui Abrogoua, Abidjan, Côte d'Ivoire ${ }^{4}$ EA 7341-LAFSET Laboratoire du froid et des systèmes thermiques CNAM, Paris, France

Email:^mitoure@cie.ci

How to cite this paper: Minayégnan, T., Oladapo, O.S., Sako, K.M., Marvillet, C. and Marvillet, C. (2021) Analysis of the Technico-Economic Viability of an Electric Micro-Grid with Renewable Electricity Production Sources in Elokato-Bingerville, Cote d'Ivoire. Smart Grid and Renewable Energy, 12, 183-202.

https://doi.org/10.4236/sgre.2021.1211011

Received: September 24, 2021

Accepted: November 27, 2021

Published: November 30, 2021

Copyright $\odot 2021$ by author(s) and Scientific Research Publishing Inc. This work is licensed under the Creative Commons Attribution International License (CC BY 4.0).

http://creativecommons.org/licenses/by/4.0/

(c) (i) Open Access

\begin{abstract}
In this study, the technico-economic viability is studied, on the basis of different scenarios of electric micro-grids with renewable energy production sources, autonomous and supplied by the interconnected grid. HOMER Pro 3.13.3 Pro simulation and optimization software, Xlstat and Energy sentinel software are used for the evaluation of different technical and economic scenarios of system components, in order to obtain the most cost-effective configuration. To do this, the case study of the village of ELOKATO identifies the optimal options for the use of renewable energies for rural electrification in order to increase the electricity coverage rate. In our case study, after the various simulations, HOMER identified 13 scenarios and configurations deemed to be the most profitable, from the parameters and configurations without photovoltaic components have high COEs and very high initial investment costs in the order of several million US \$. Renewable energy power generators require high initial investments and relatively low operating costs. The most important costs are generated by the battery park and then come the photovoltaic panels. The hybrid PV/wind/diesel/hydropower system is profitable if the distance from the village to the transformer station is greater than $1.90 \mathrm{~km}$. The results show great potential for using these hybridized production sources with or without a generator to meet the electricity needs of a village.
\end{abstract}

\section{Keywords}

Renewable Energies, Rural Electrification, Homer Pro, Elokato, XLSTAT 


\section{Introduction}

Africa will see its population double in 30 years to reach nearly 2.5 billion inhabitants by 2050. Many people identify the economic development of countries on the African continent as the main response to this exponential population growth.

Africa will experience a period of sustained and unprecedented growth. By 2050 , the continent will have a population of at least 2 billion people (twice as many as today), $40 \%$ of whom will be in rural areas [1].

About 645 million Africans do not have access to electricity. Per capita, energy consumption in sub-Saharan Africa is currently estimated at 181 kilowatts per year, the lowest of any continent compared to that of Europe and the United States of America, which are 6500 kilowatts and 13,000 respectively kilowatts per year. The loss of $2 \%$ and $4 \%$ of the GDP in Africa is estimated, in particular, by the shortage of electricity in the energy sector, which significantly slows down economic growth, job creation and investment [2].

If energy trends do not change, in 2030 Africa will still have 655 million people ( $42 \%$ of the population) without access to electricity and 866 million (56\% of the population) people without clean fuels and cooking technologies, leaving the majority of the population deprived of the right to a more productive and healthy life. $2 / 3$ of these populations live in rural areas without access to the national electricity grid.

Connection to the network is unaffordable and sometimes unreliable. We must therefore consider other alternatives.

Cote d'Ivoire has very early developed a policy of access to electricity based on the exploitation of its hydraulic and thermal resources.

Rural electrification is one of the major axes of the Ivorian Government's economic and social policy. To this end, this sub-sector has benefited from constant historical support from the public authorities. The major programs initiated by Côte d'Ivoire, which had only 14 electrified localities in 1960, saw the number of villages supplied with electric energy reach 2847 in 2011, then 4972 at the end of 2017, making the coverage rate (Number of electrified localities/Total number of localities) at about $54 \%$ while the rate of access to electricity (Population living in electrified localities/Total population) is around 81\% [3] (Figure 1).

These results are certainly encouraging, but still quite weak. Moreover, from another point of view, even if the progress is good as confirmed by the authorities of the sector, it still faces difficulties related to the allocated resources, which difficulties should be overcome by the mobilization of more resources to accelerate the implementation of this program and then extend it to the small rural community.

Indeed, of the 8513 localities in Cote d'Ivoire, there are still 4555 non-electrified localities [4]. However, Cote d'Ivoire has varied and sufficient natural energy resources to meet its own energy needs through the implementation of an appropriate energy policy and master plan. 


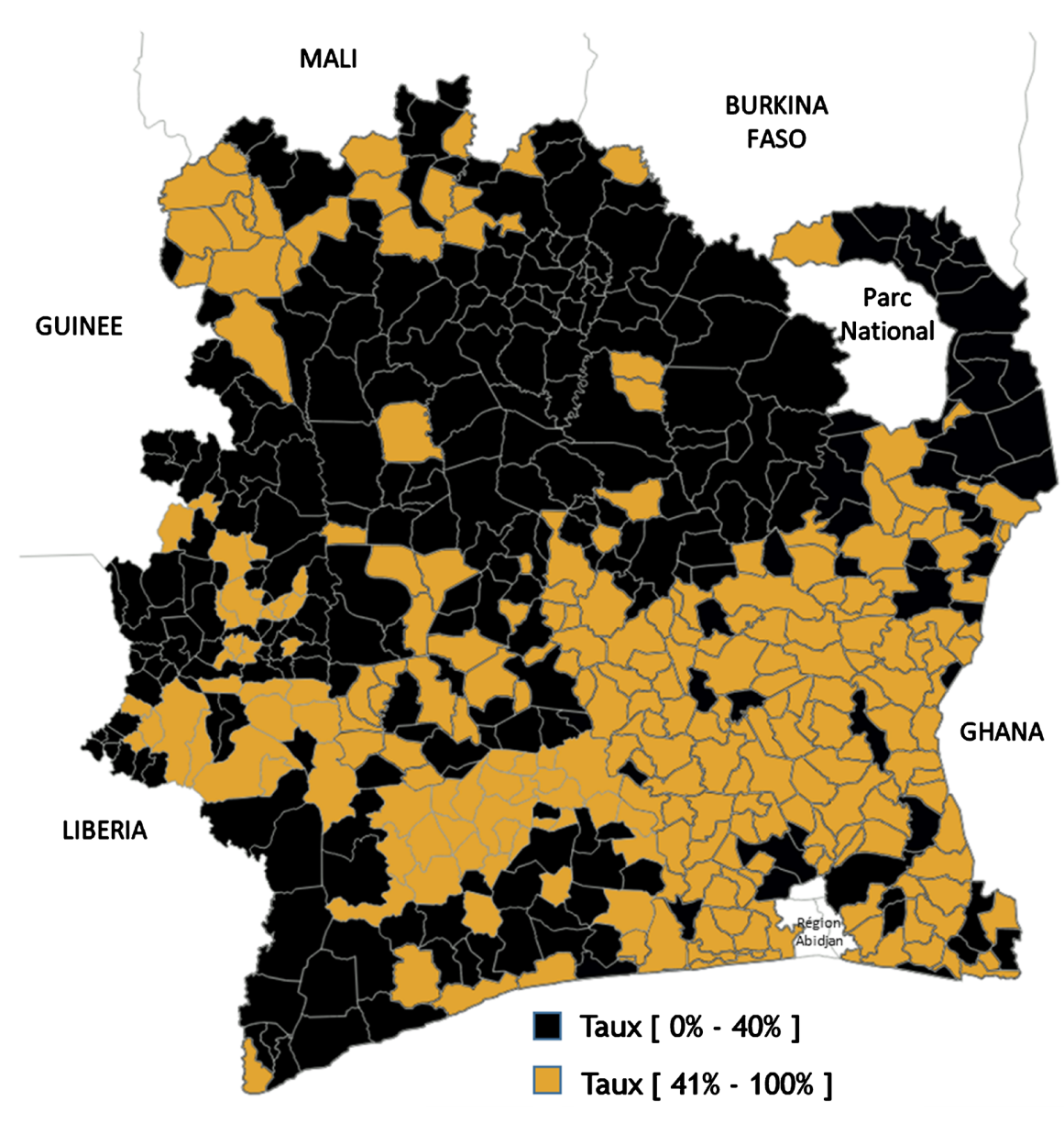

Sources: CIE, CI-ENERGIES, 2017.

Figure 1. Rate of electrified area.

In addition, the Rural Electrification Program (PRONER) and viable master plan remain at the center of the concerns of the country, which is committed to continuing and amplifying the works at the rate of a minimum of 500 new localities electrified each year, in order to achieve the goal of total electrification of Côte d'Ivoire by 2025 .

We must therefore use all the advantages offered by renewable energies and maximize all the economic, technological and environmental benefits that they can provide.

However, if the technologies and operating modes of conventional electricity systems are known and sometimes predictable, this is not the case for renewable energy micro-grids because their operating modes and their output powers are influenced by meteorology and climatic conditions

Also despite the abundant solar energy, with a daily sunshine time of 6 , the capital cost of PV systems has always been the main barrier to the use of solar energy However, PV alone cannot supply energy at noon and therefore has to be supported by alternative energy sources such batterie as wind and/or genset, and others.

Many researchers have extensively studied micro-grid systems based on re- 
newable energies. Several studies [5] [6] [7] [8] [9] have shown that the use of renewable energy would make it possible to electrify these isolated rural areas.

Other work [7] [8] [9] [10] has focused on optimizing, planning, and managing the design of a renewable energy-based hybrid microgrid with the aim of minimizing the life cycle cost. The results showed that the mixed renewable and diesel micro-grids would have the lowest life cycle cost and a relatively low carbon footprint.

To the best of our knowledge, any paper focuses on the economic viability of an electric micro-grid with renewable electricity in Western Africa

Our study focuses on the analysis of the technical and economic viability of an electric micro-grid with renewable electricity production sources in ElokatoBingerville, a village of Côte d'Ivoire. We use lots of professional software with authorized license to do the simulations and measures.

This paper presents the result of the simulation of 13 scenarios and configurations deemed to be most profitable for our microgrid.

The rest of the paper consists of the following main sections. Section 2 presents the characteristic of software used a. The methodology is presented in Section 3. Section 4 describes the result and discussion.

The conditions for the success of our project consisted in identifying a voluntary village, as an experimental site, not far from the Abidjan, capital of Cote d'Ivoire.

This site should allow the installation of a metering plan for the needs assessment and meet the following criteria (Figure 2):

- Easy access to the village;

- Proximity to the village of Abidjan (capital of Cote d'Ivoire);

- People's support for the renewable energy project;

- Availability of energy resources (wind, streams, biomass, low solar deposit compared to the rest of the country).

\section{The Characteristic of Software}

\subsection{Homer Pro}

The HOMER Pro 3.13.3 micro-grid simulation software, developed by the National

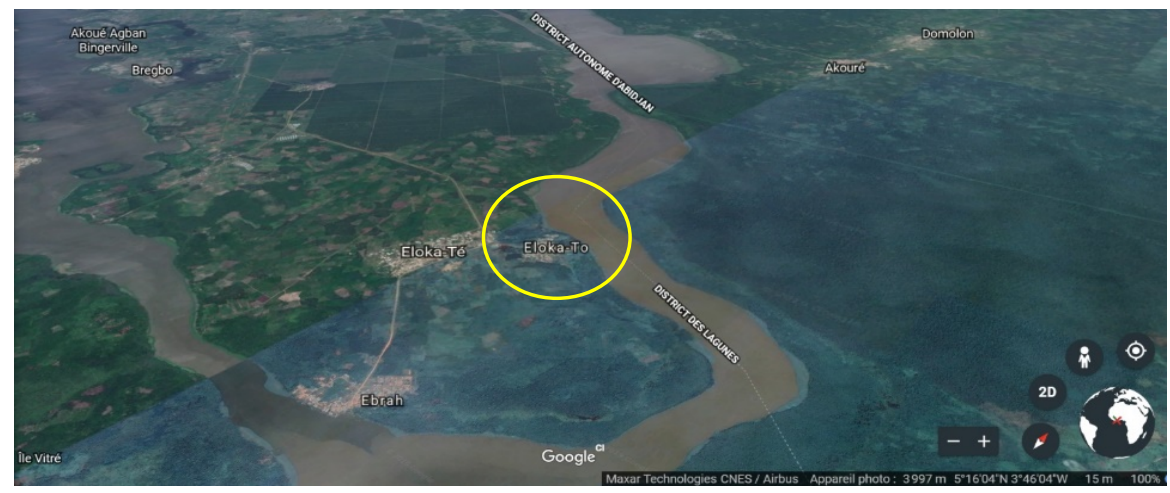

Figure 2. Geographical location of the village of Elokato [Google map]. 
Renewable Energy Laboratory in the United States, is used for this study, it is an essential decision support tool for projects optimized design of decentralized micro-grids. In this area it is one of the most widely used standards in the world.

This tool is used in all sectors, from electricity supply in isolated villages and island utilities to sites connected to the grid. Homer Pro, or HOMER (Hybrid Optimization of Multiple Electric Renewable Energies), provides outstanding assistance by simplifying the design assessment tasks of off-grid and grid-connected power systems. It allows you to select the best system components and identify for each component the effective sizes and characteristics to meet the energy needs of the site.

In its operation, HOMER requires input data on daily needs (kWh/day), parameters of available energy resources of the site studied, an architectural proposal for the components of the micro-grid, economic indicators and environmental data. The software uses these inputs to simulate different system configurations or combinations of components and generates displayable results as a list of achievable configurations ordered by current net cost. HOMER also displays simulation results in a variety of tables and graphs to compare configurations and evaluate them economically and technically. It also allows for sensitivity analyzes to explore the impacts of changes in factors, such as resource availability and economic conditions, on the cost-effectiveness of different system configurations [11].

\subsection{Xlstat}

XLSTAT is statistical management software that integrates and relies on Microsoft Excel for data entry and publication of results. The calculations are carried out entirely in autonomous programs and algorithms. Using Excel as an interface makes the application very user-friendly, intuitive and robust. The quality, precision and relevance of the calculations are identical to those of renowned scientific software. XLSTAT is compatible with all versions of Excel since version 97 under Windows and Mac environments. The 2018 versions integrate a lot of useful features such as the $\mathrm{R}$ language and machine learning, which give it great computational robustness. The many features offered by XLSTAT make Excel an excellent tool for statistical analysis and modeling, making it possible to cover all data processing needs. In this study we will mainly use the descriptive statistics interface for the significance of the data.

\subsection{Energy Sentinel Software (Energy Team, Italy)}

As part of this study, for the collection of real-time data, a metering devicewas set up and connected to the power transformer that supplies the village of Elokato with electricity. Energy sentinel is the proprietary software of the Italian smart metering system supplier Energy Team (Figure 3).

The counting system is a microcontroller called X-METER which allows data acquisition through sensors and probes. These data are stored on a remote data 
server connected to the Internet (cloud) and viewable by secure access (Figure 4).

HOMER Pro 3.13.3 software is used for the simulation and optimization of the microgrid to be planned. It provides an overview of the different configurations and combinations of possible production sources in order to minimize the costs of micro-grid components.

The energy resources available, easily mobilized on the Elokato site, to produce electricity are solar photovoltaic, hydraulic (small hydro) and wind sources.

The following sessions provide more details on the resources and components to build an electricity production system from renewable sources (solar, wind, tidal)
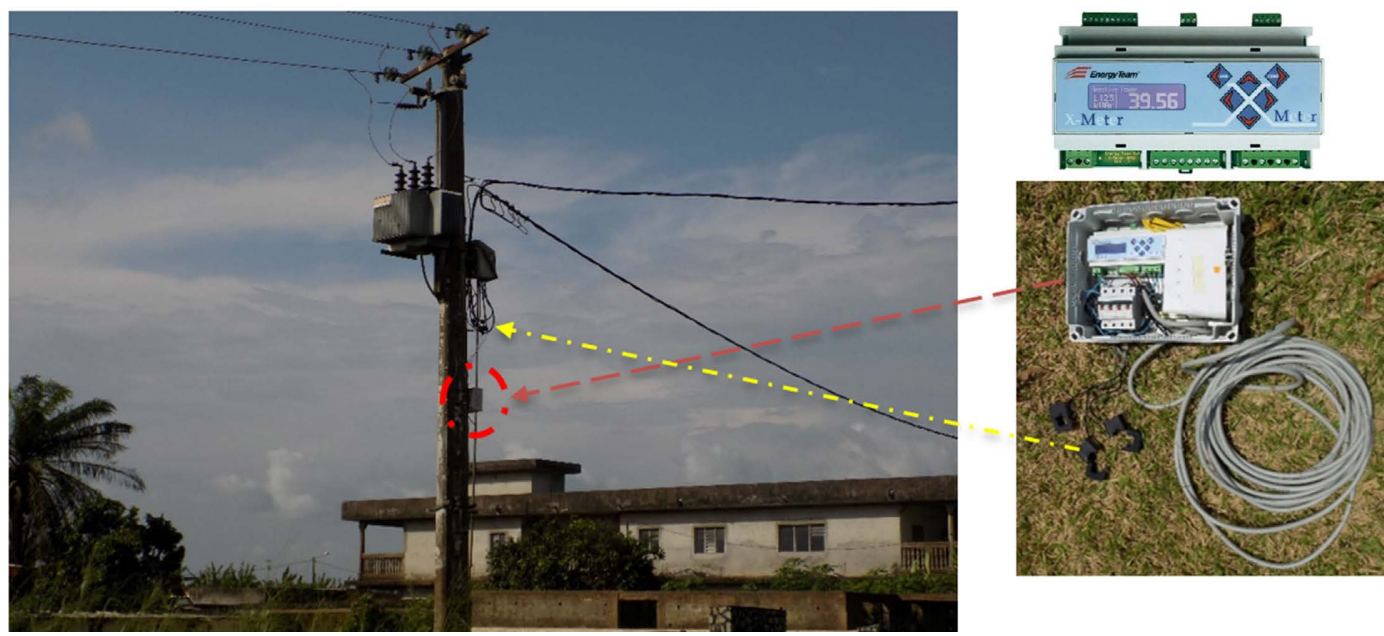

Figure 3. Metering system-Power transformer and X-METER microcontroller.

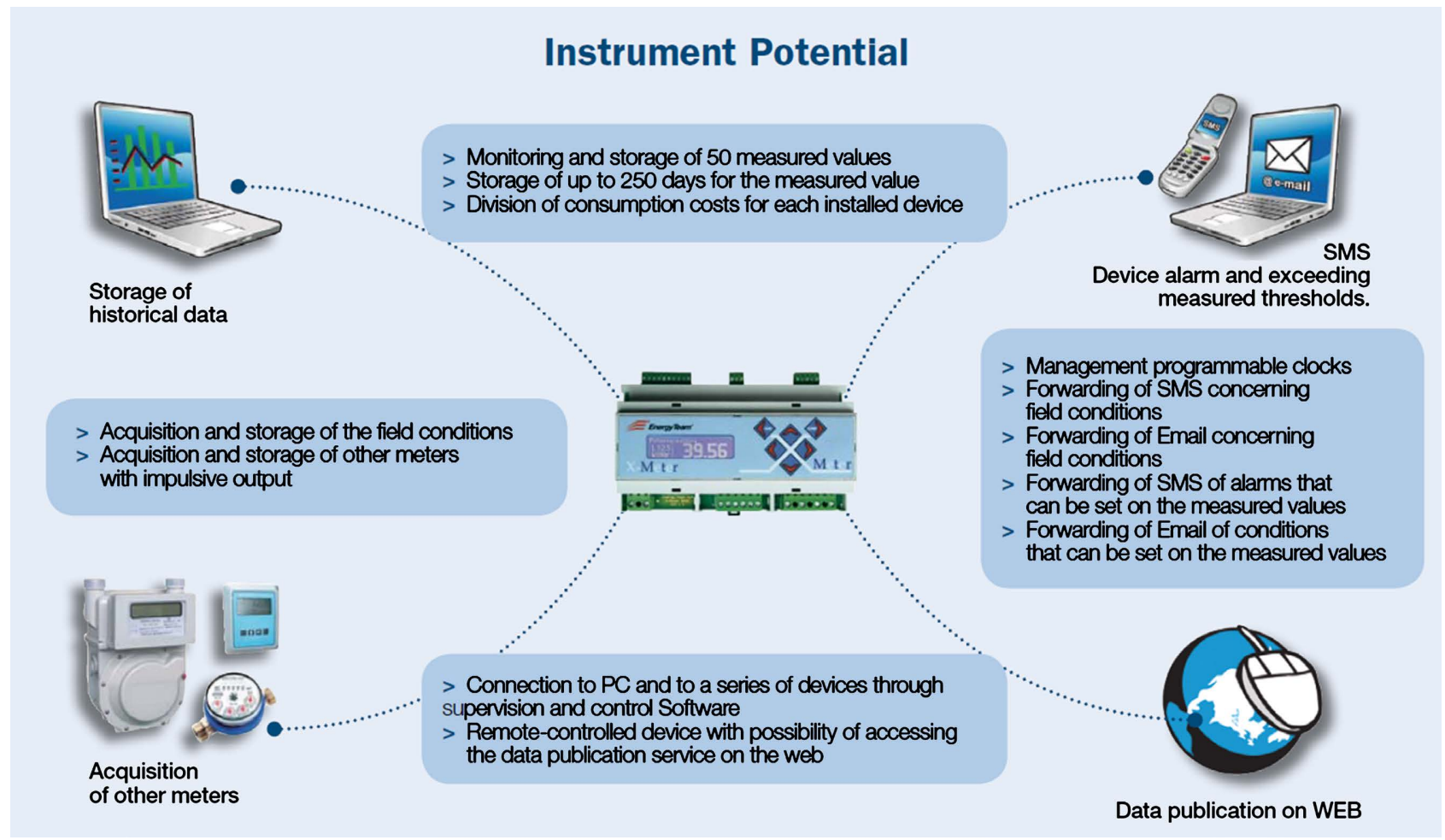

Figure 4. The potentials of the X-METER. 


\section{Methodology}

\subsection{Data Collection and Major Components of the System}

\section{The electrical load to be covered}

The identification and analysis of demand remain the most important steps in the design and sizing of a micro-grid, it will determine the scope of the production system to be built.

The village of ELOKATO is connected to the national electricity grid. To obtain real consumption values, a measurement system is installed at the level of the power transformer, of the H61-15kV/400V/100kVA type of apparent power, which supplies the village.

An Energy team X-METER type metering device, installed on the site since 2018, has made it possible to take remote readings of 50 electrical quantities (current, voltage, power, energy, etc.) quantitatively and qualitatively. The village's consumption was recorded on a computer in time steps ( $1 \mathrm{~min}, 10 \mathrm{~min}, 15$ $\mathrm{min}, 30 \mathrm{~min}, 60 \mathrm{~min}$ ) for more than a year.

All of this data has been exported to Microsoft Excel.

A comparison of consumption readings by the X-METER type meter is made with the conventional low-voltage billing system installed at all customers of the Ivorian Electricity Company (CIE) to assess the consistency of the data collected.

These data were formatted and then imported into HOMER Pro, as village consumption reference values, in time steps of 1 hour as input parameters to establish the daily load profile [8760 lines of data] (Figure 5).

Profile (daily, monthly, annual)_ELOKATO village

The daily loads follow a concentrated distribution mainly more at night than during the day: a first tranche from $6 \mathrm{pm}$ to $11 \mathrm{pm}$ and a second tranche from midnight to $6 \mathrm{am}$. The peak load is observed between $8 \mathrm{p} . \mathrm{m}$. and $10 \mathrm{p} . \mathrm{m}$.

The average daily consumption recorded over a year is $662.08 \mathrm{kWh} /$ day for an alternating load (AC).

As the curve shows, the annual peak of consumption is observed in the month of December (Figure 6).

Electricity needs are highest during the first and last quarter of the year, which

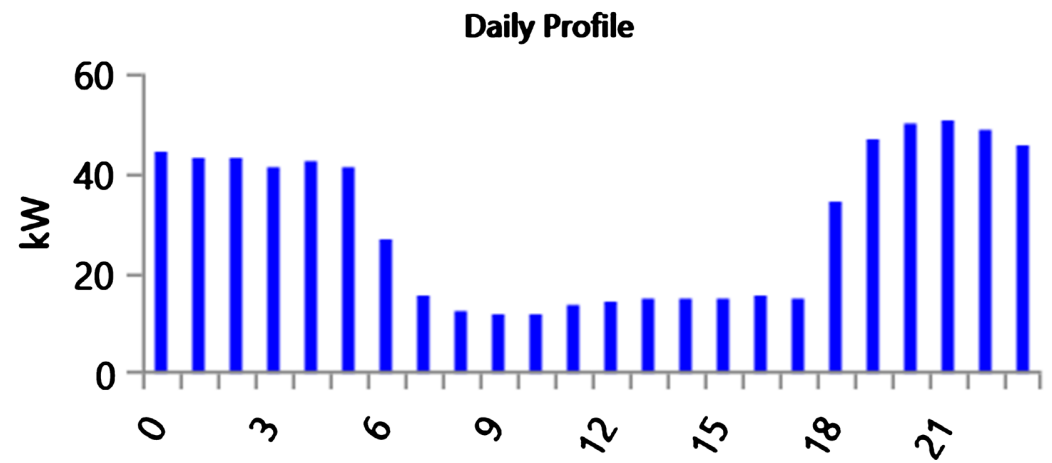

Source: Homer Energy 3.13.2 Pro.

Figure 5. Electricity consumption-Daily profile. 
correspond respectively to the period of high heat and the end of year holiday period (generation, cultural, etc.) (Figure 7).

\section{Major components of the system}

The essential components of the hybrid system for the micro-grid within the framework of this project are: a photovoltaic system, a wind turbine, a chemical storage system (battery), a diesel generator, the national grid, a DC/AC converter (Figure 8).

\section{Seasonal Profile}

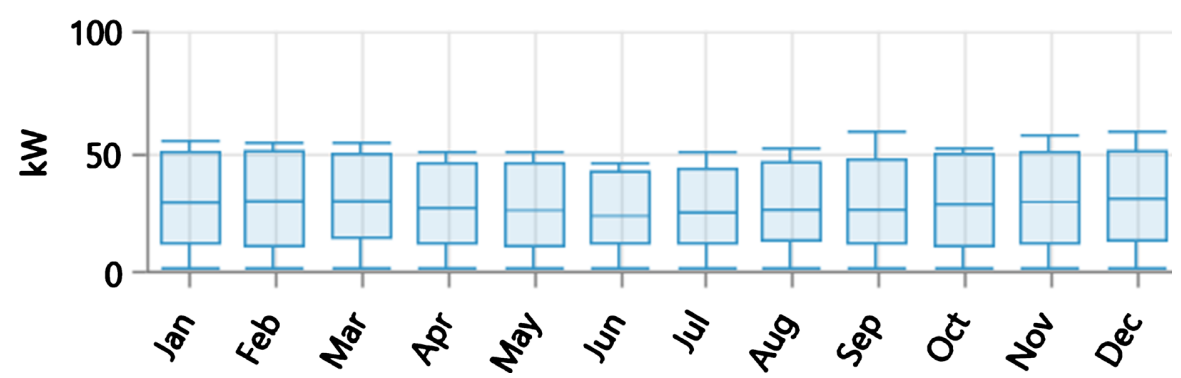

Figure 6. Electricity consumption-Monthly profile.

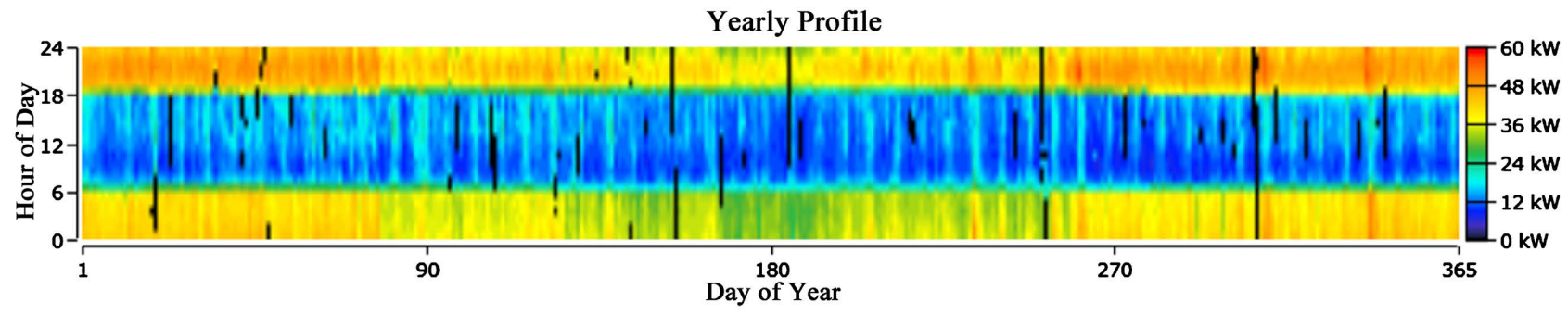

Figure 7. Consommation d'électricité-Profil Annuel.

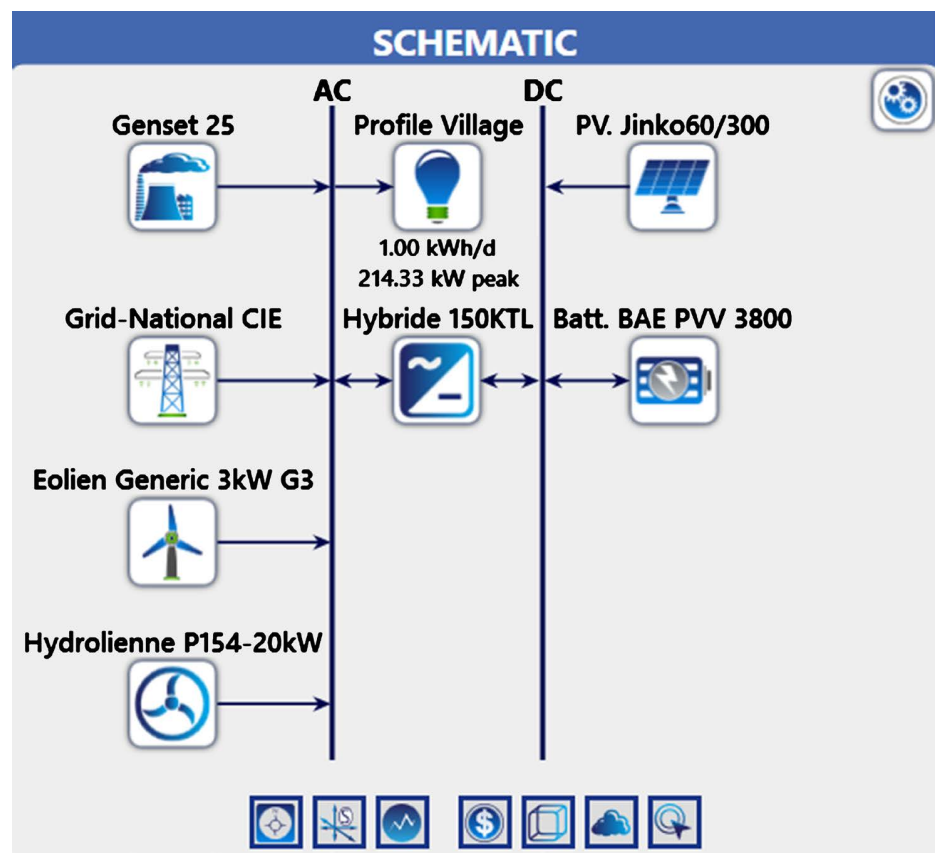

Figure 8. Mini-grid component diagram in HOMER Pro. 
Photovoltaic panel

Solar irradiation

Not having complete data, localy measured over one year from the study site. We choose to use the solar irradiation and light data for the village of Elokato come from the American national database of the National Solar Radiation Database (Figure 9).

The global annual horizontal solar radiation is shown in Figure 9. The daily average over the year is $4.76 \mathrm{kWh} / \mathrm{m}^{2}$.

\section{Photovoltaic (PV) module}

For the study, the chosen PV module is of the monocrystalline silicon type, manufactured by Jinko Solar (Table 1).

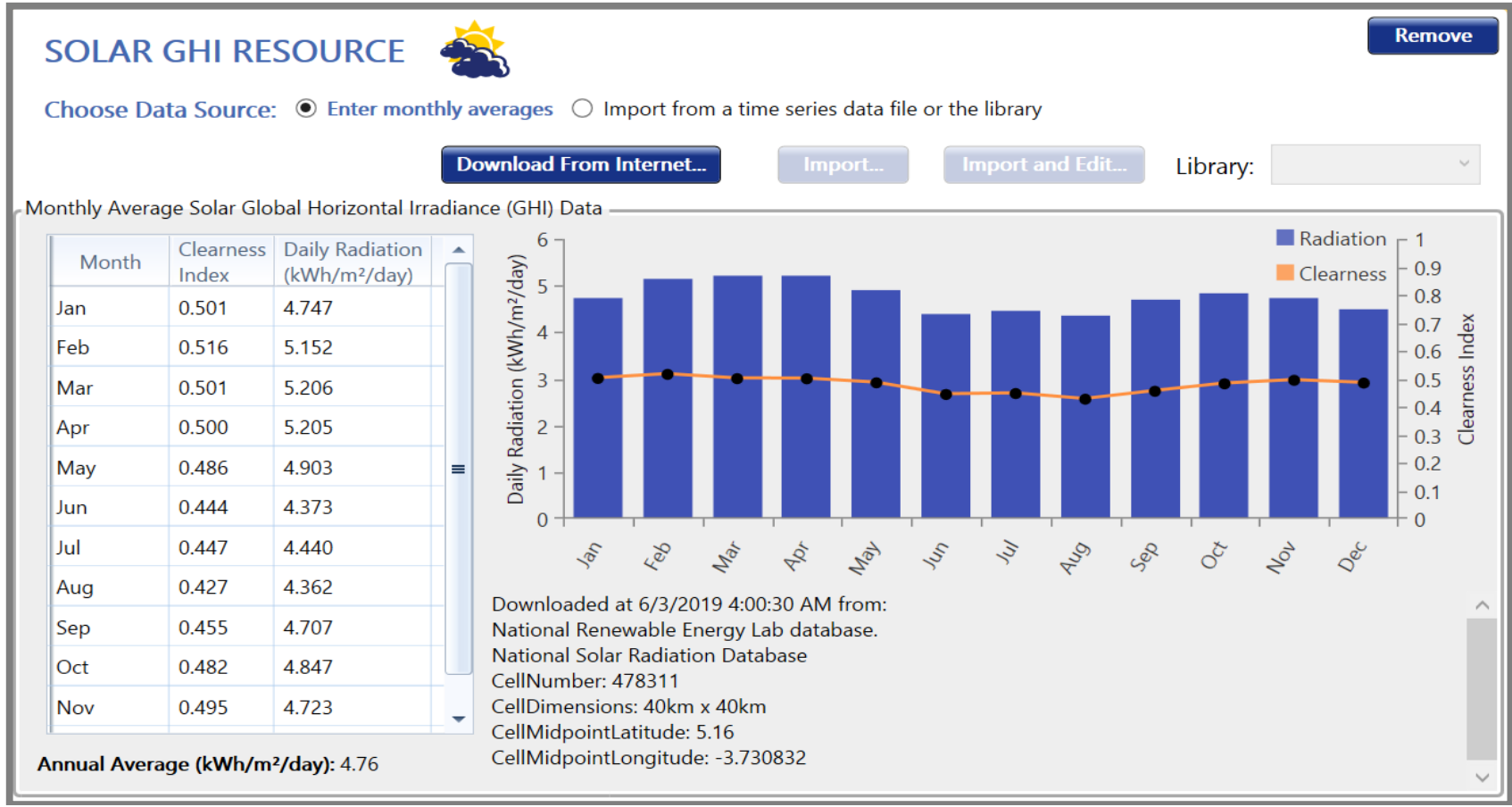

Figure 9. Annual horizontal solar radiation.

Table 1. Cost elements of the photovoltaic generator chosen for ELOKATO.

\begin{tabular}{|c|c|c|c|}
\hline \multicolumn{4}{|c|}{ COMPOSANTS } \\
\hline & Caracteristics & $S T C$ & NOCT \\
\hline \multirow{5}{*}{$\begin{array}{c}\text { Module Photovoltaïque } \\
(P V)\end{array}$} & Maximum Power (Pmax) & $300 \mathrm{Wp}$ & $224 \mathrm{Wp}$ \\
\hline & Maximum Power Voltage (Vmp) & $32.6 \mathrm{~V}$ & $30.6 \mathrm{~V}$ \\
\hline & Maximum Power Current (Imp) & $9.21 \mathrm{~A}$ & $7.32 \mathrm{~A}$ \\
\hline & Open-circuit Voltage (Voc) & $40.1 \mathrm{~V}$ & $37.0 \mathrm{~V}$ \\
\hline & Short-circuit Current (Isc) & $9.72 \mathrm{~A}$ & $8.01 \mathrm{~A}$ \\
\hline \multirow{2}{*}{$\begin{array}{l}\text { Mono-crystalline PERC } \\
156 \times 156 \mathrm{~mm}(6 \mathrm{inch})\end{array}$} & Module Efficiency STC (\%) & $18.33 \%$ & $18.33 \%$ \\
\hline & Operating Temperature $\left({ }^{\circ} \mathrm{C}\right)$ & \multicolumn{2}{|c|}{$-40^{\circ} \mathrm{C} \sim+85^{\circ} \mathrm{C}$} \\
\hline
\end{tabular}




\begin{tabular}{lcc}
\hline & Maximum system voltage & 1000VDC (IEC) \\
Maximum series fuse rating & $15 \mathrm{~A}$ \\
Power tolerance & $0 \sim+3 \%$ \\
Temperature coefficients of Pmax & $-0.39 \% /{ }^{\circ} \mathrm{C}$ \\
Temperature coefficients of Voc & $-0.29 \% /{ }^{\circ} \mathrm{C}$ \\
Temperature coefficients of Isc & $0.05 \% /{ }^{\circ} \mathrm{C}$ \\
& Nominal operating cell temperature (NOCT) & $45^{\circ} \mathrm{C} \pm 2^{\circ} \mathrm{C}$ \\
& Costing Input data in HOMER & \\
- Cost & Capital (\$) & $\$ 214,947$ \\
& Remplacement (\$) & $\$ 164,086.52$ \\
Operation and Maintenance (\$) & $\$ 3000$ \\
Lite Specific Input & Derating Factor $(\%)$ & 25 \\
& Electrical Bus & $88 \%$ \\
\hline
\end{tabular}

The derating factor that was applied to calculate the reduced power output under actual operating conditions compared to rated conditions is $88 \%$ (Figure 10).

\section{Wind turbine}

The wind generator used for the simulations is of the generic type Eolien Generic $3 \mathrm{~kW}-\mathrm{G} 3$ from the HOMER Energy database. It is a $3 \mathrm{~kW}$ wind turbine connected to the AC bus (Figure 11).

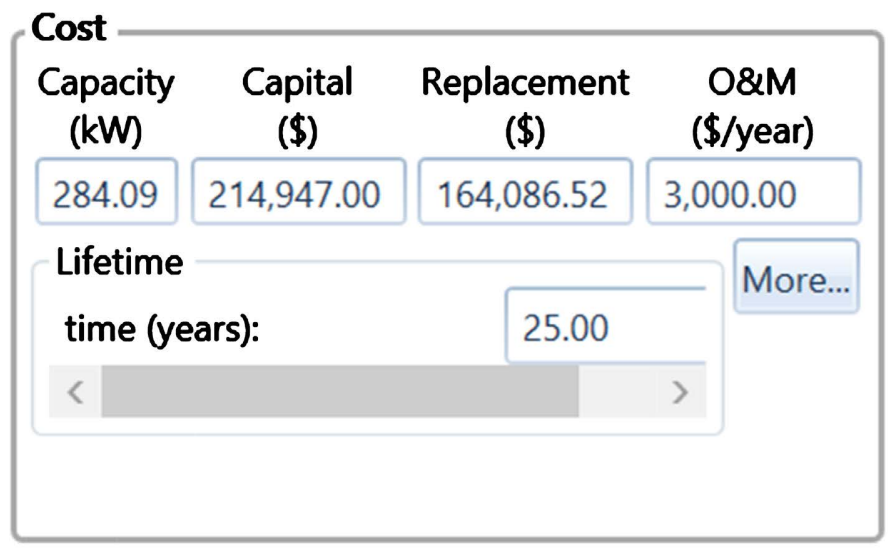

Figure 10. Cost elements of the photovoltaic generator chosen for ELOKATO.

\begin{tabular}{|c|c|c|c|c|}
\hline Quantity & $\begin{array}{c}\text { Capital } \\
(\$)\end{array}$ & $\begin{array}{c}\text { Replacement } \\
(\$)\end{array}$ & $\begin{array}{c}\text { O\&M } \\
\text { (\$/year) }\end{array}$ & \\
\hline 1 & $\$ 18,000.00$ & $\$ 18,000.00$ & $\$ 180.00$ & 2 \\
\hline \multicolumn{5}{|c|}{ Click here to add new item } \\
\hline \multicolumn{5}{|l|}{ Multiplier: } \\
\hline
\end{tabular}

Figure 11. Cost elements of the wind generator chosen for ELOKATO. 
The values used in this study are taken from NASA metrological data available in the HOMER Pro database. The average annual speed was about $3.28 \mathrm{~m} / \mathrm{s}$, measured at an anemometer height of $50 \mathrm{~m}$ (Figure 12).

HOMER calculates the output power of the wind turbine at each time step using a three-step process:

- Calculation of the wind speed at the height of the hub of the wind turbine.

- Calculation of the amount of energy produced by the wind turbine at this wind speed with a standard air density.

- Adjustment of the power value according to the real air density.

\section{Turbine}

A $20 \mathrm{~kW}$ Guinard Energies tidal turbine (P154) was chosen as the source of hydraulic production within the framework of this study. It is a generator connected to the AC bus, with the following characteristics:

- Dimensions: $2 \mathrm{~m} \times 3 \mathrm{~m}$;

- Weight: $750 \mathrm{~kg}$;

- Rotor diameter: $1540 \mathrm{~mm}$;

- Required immersion depth: $3 \mathrm{~m}$;

\section{Storage System}

The chosen battery model has the following characteristics:

- Type: Kinetic Battery Model-The BAE SECURA Solar 20PVVV3800-OPZV battery is a sealed, maintenance-free gel battery and requiring no water filling

- Nominal voltage: $2 \mathrm{~V}$;

- Nominal capacity: $7.37 \mathrm{kWh}$;

- Maximum capacity: $3800 \mathrm{Ah}$;

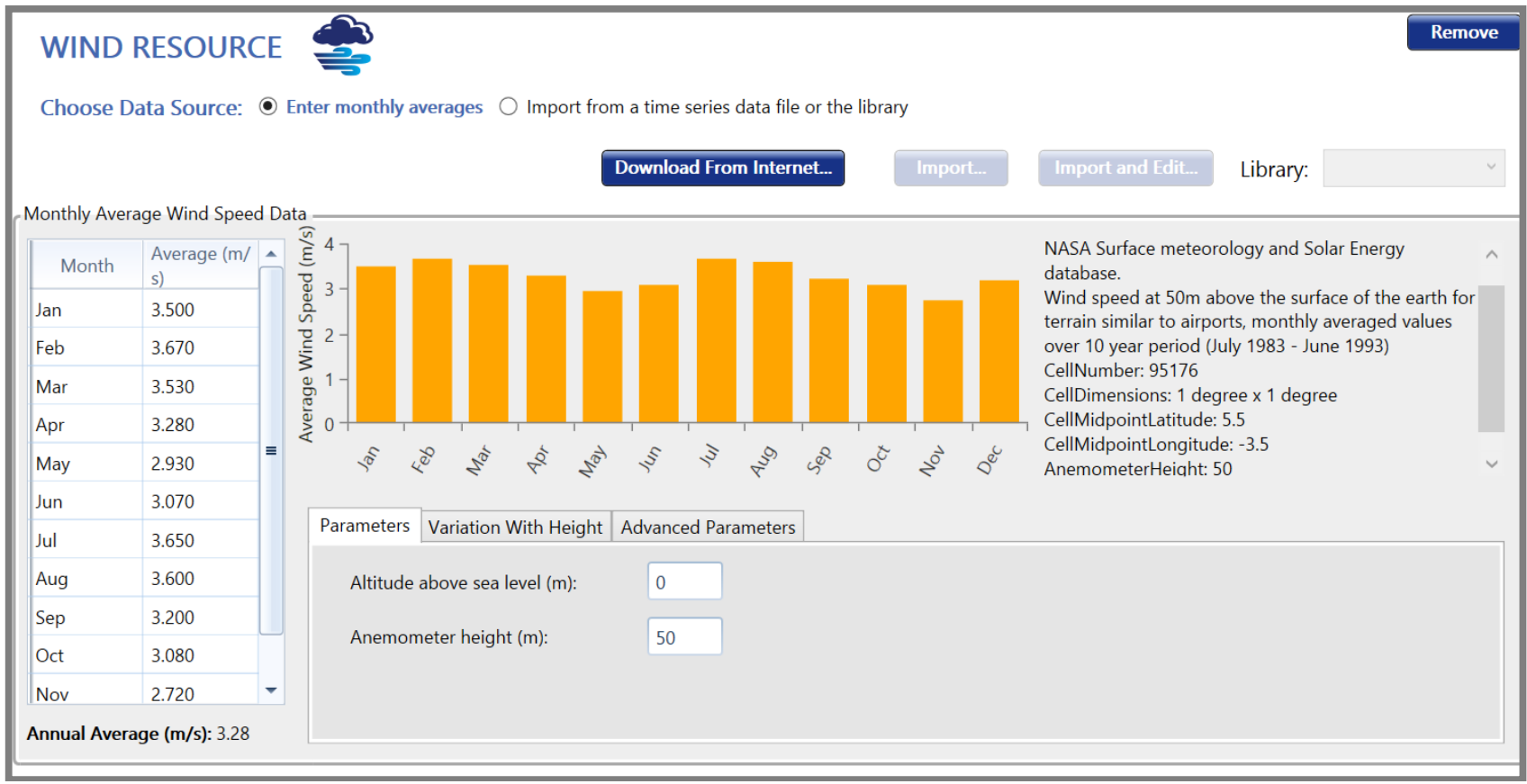

Figure 12. Monthly average wind speed data ELOKATO. 
- Minimum statement of charge (SOC): $30 \%$;

- The storage system is wired in $48 \mathrm{~V}$;

- Number of thongs: 24;

- Manufacturer: BAE Secura PVV Solar Batteries (Figures 13-15).

Generator

To improve the reliability of the $25 \mathrm{KW}$ diesel generator system has been chosen. It is a connected generator on the AC bus (Figure 16 \& Figure 17).

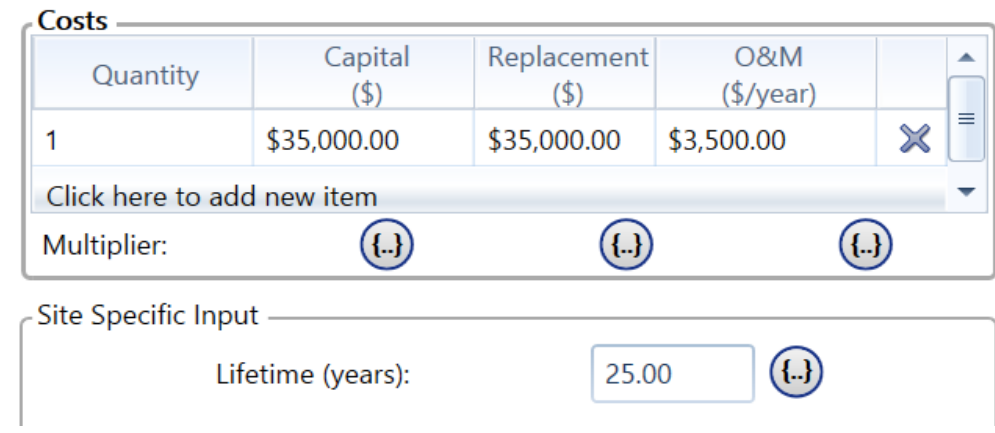

Figure 13. Cost elements of the tidal turbine generator chosen for ELOKATO.

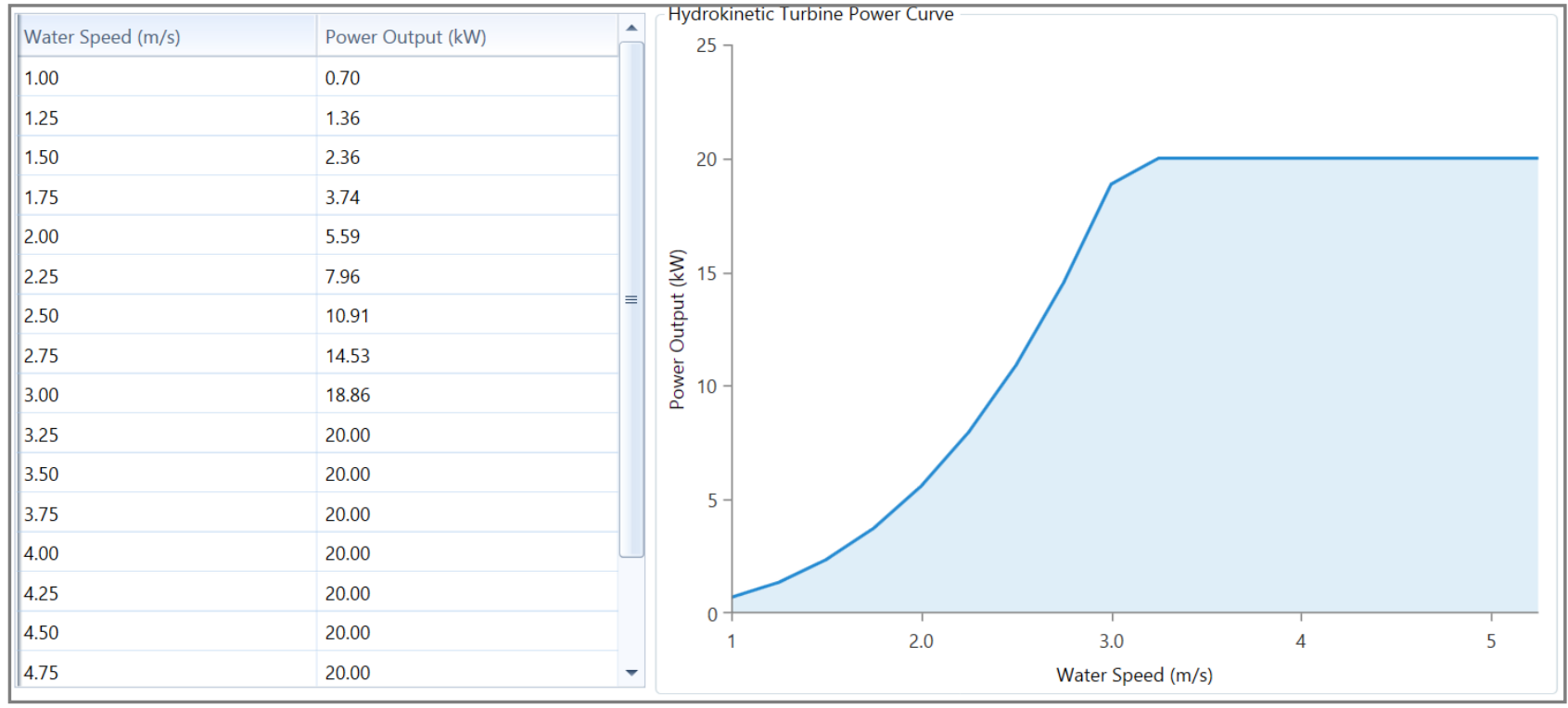

Figure 14. Characteristic curve of the selected wind generator for Elokato.

\begin{tabular}{|c|c|c|c|c|}
\hline Quantity & $\begin{array}{c}\text { Capital } \\
(\$)\end{array}$ & $\begin{array}{c}\text { Replacement } \\
(\$)\end{array}$ & \multicolumn{2}{|c|}{$\begin{array}{c}\text { O\&M } \\
\text { (\$/year) }\end{array}$} \\
\hline 24 & $25,187.96$ & $25,187.96$ & $1,500.00$ & \\
\hline \multicolumn{4}{|c|}{ Lifetime } & \multirow{3}{*}{ More... } \\
\hline \multirow{2}{*}{\multicolumn{2}{|c|}{$\begin{array}{l}\text { throughput (kWh): } \\
\text { time (years): }\end{array}$}} & $81,982.42$ & \multirow{2}{*}{$\begin{array}{l}\text { (27) } \\
\text { (1..\} }\end{array}$} & \\
\hline & & 25.00 & & \\
\hline
\end{tabular}

Figure 15. Cost elements of the storage system (batteries) chosen. 


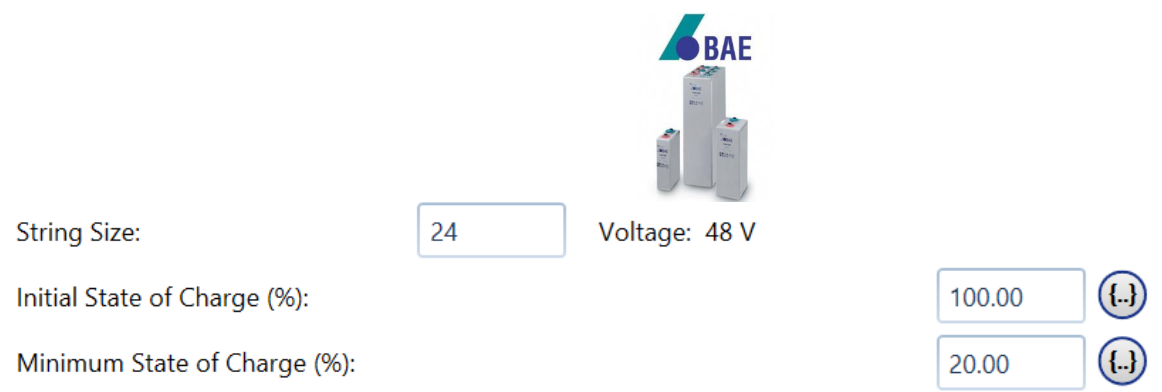

Figure 16. Caractéristiques du système de stockage

$\begin{cases}\text { Generator Cost } & \\ \text { Initial Capital (\$): } & 12,500.00 \\ \text { Replacement (\$): } & 12,500.00 \\ \text { O\&M (\$/op. hour): } & 0.750 \\ \text { Fuel Price (\$/L): } & 1.200\end{cases}$

Figure 17. Cost elements of the electorate group chosen for Elokato.

\subsection{Criteria for Evaluating the Technical and Economic Performance of the System}

As part of this study, the indicators of economic viability, technical reliability and environmental impact have been used as criteria for evaluating the technical and economic performance of the system.

\subsubsection{Economic Viability Indicator}

The cost of the life cycle is taken as an indicator of optimizing and evaluating the economic performance of the Elokato Village Micro-Network System. To assess the economic benefits, the operating costs of the system, and the initial and replacement costs have been taken into account. In the Homer approach, the current total net cost (NPC) is equivalent to the cost of the system life cycle, this cost is composed of all costs incurred during the life of the micro-network. The NPC has made it possible to schedule and find the scenarios at minimum cost. The NPC is obtained by deducting income from the current value the expenses incurred during the life of the micro-network. The total net cost to be taken into account is the sum of the costs of initial capital, the costs of replacement, the costs associated with the operation and maintenance, the cost of the purchase of fuel and electricity, and taxes on the polluting emissions. Total products consists of the recovery value at the closing of the project and revenues from the commercialization of electricity in the network.

The COE (COST OF ENERGY) and $F$ (Capital Recovery Factor) make it possible to make a relevant NPC assessment, the equations below can be used [11]: 


$$
C_{N P C}=\frac{C_{T A C}}{f}
$$

where: $C_{T A C}$ is the total annualized cost; $f$ is the capital recovery factor, given by the equation

$$
C O E=\frac{C_{T A C}}{E_{\text {Load }}+E_{\text {grid,sales }}}
$$

where: $E_{\text {demand }}$ is the annualized load served by the micro-grid $\left[\mathrm{kW} \mathrm{h/y];} E_{\text {vente }}\right.$ vente are the energies sold to the interconnected network per year $[\mathrm{kWh} / \mathrm{y}]$. In our case study, no sale is yet possible on the interconnected network in Ivory Coast for the moment.

$$
f=\frac{i(1+i)^{N}}{(1+i)^{N}-1}
$$

$i$ : annual interest rate; $N$ : Number of years

\section{- Grid extension distance at equilibrium: Mini-grid versus Interconnected grid}

The equilibrium grid extension distance is the distance from the grid that makes the current net cost of extending the grid equal to the current net cost of the autonomous system. Further away from the network, the autonomous system is optimal. Closer to the grid, the extension of the grid is optimal.

HOMER calculates the break-even extension distance using the following equation:

$$
D_{\text {grid }}=\frac{C_{N P C} \cdot \operatorname{CRF}\left(i, R_{\text {proj }}\right)-C_{\text {power }} \cdot E_{\text {demand }}}{C_{c a p} \cdot \operatorname{CRF}\left(i, R_{\text {proj }}\right)+C_{o m}}
$$

where:

$C_{\mathrm{NPC}}=$ current net total cost of the off-grid power system [\$];

$\mathrm{CRF}()=$ capital recovery factor;

$i=$ real discount rate [\%];

$R_{\text {proj }}=$ lifetime of the project [year];

$E_{\text {demand }}=$ total annual electrical demand (primary plus differentiation) $[\mathrm{kWh} /$ year $]$;

$c_{\text {power }}=$ cost of grid electricity $[\$ / \mathrm{kWh}]$;

$c_{\text {cap }}=$ capital cost of network extension $[\$ / \mathrm{km}]$;

$c_{o m}=$ Network extension operation and maintenance cost $[\$ /$ year $/ \mathrm{km}]$.

\subsubsection{Indicator of Technological Reliability}

The fraction of capacity shortage or capacity insufficiency is chosen as an indicator to assess the technological reliability performance of the micro-grid. The capacity shortage fraction is the ratio between the total shortage and the total demand for electricity, this value must be between 0 and 1 . The technological reliability of the system is high when this ratio tends towards 0 . In our case of study a maximum of $5 \%$ has been set as a target (Figure 18).

The calculation of the value of the capacity shortage is done with the following 


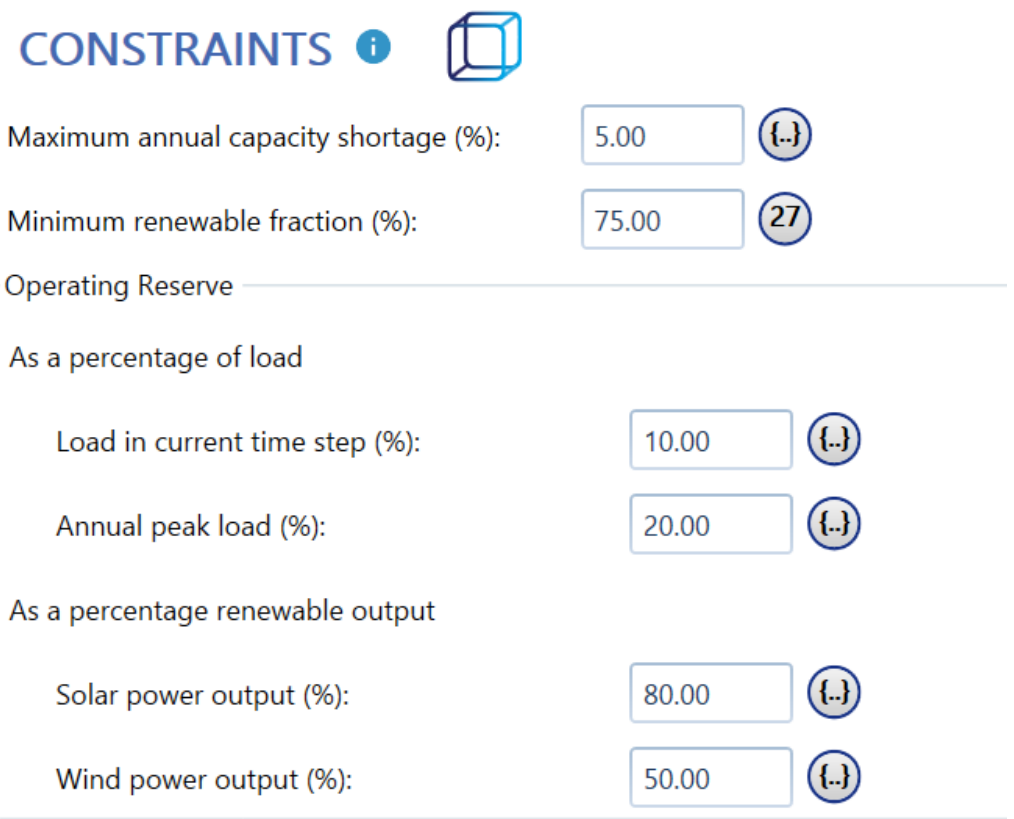

Figure 18. Objective value of the capacity shortage indicator.

equation:

$$
F_{C S}=\frac{E_{C S}}{E_{\text {demand }}} \leq 5 \%
$$

where: $E_{c s}$ is the total capacity shortage $[\mathrm{kWh} / \mathrm{y}], E_{\text {demand }}$ is the total electricity demand $[\mathrm{kWh} / \mathrm{y}]$.

\section{Environmental impact indicator}

The renewable fraction is the indicator chosen for the evaluation of the environmental impact of this micro-grid. The diesel generator using fossil fuels and the external networks are the main emitters of air pollutants. To evaluate this indicator the formula below is used [9],

$$
F_{\text {ren }}=1-\frac{\left(E_{\text {nonren }}-E_{g s}\right)+H_{\text {nonren }}}{E_{\text {ser }}+H_{\text {ser }}}
$$

where: $E_{\text {nonren }}$ is the non-renewable electricity production $[\mathrm{kWh} / \mathrm{y}], H_{\text {nonren }}$ is the non-renewable thermal production $[\mathrm{kWh} / \mathrm{y}], E_{g s}$ is the energy sold to the interconnected grid [kWh/y], $E_{\text {ser }}$ is the total electrical load served [kWh/a], $H_{\text {ser }}$ is the total heat load supplied [kWh/y].

The life of the project has been set at 25 years, with an annual real interest rate of 5.88, which is used to calculate discount factors and annualized costs from net current costs [11].

In HOMER, two main storage system management strategies are used to administer the operation of the generator set and battery bank when there is a shortage of renewable energy production to meet the load: duty cycle (CC) and monitoring. load (LF).

- For the Load Following (LF) strategy, whenever the generator set is running, 
only the power needed for charging (demand) can be generated and the battery bank cannot be charged.

- For the cyclic charging (CC) strategy, the generator set will operate at maximum capacity and the excess power generated will be used to charge the battery bank [11].

The strategy adopted in this study is LF (load monitoring), which means that the batteries would be charged by the PV field, the wind turbine and the tidal turbine only by the excess of production after satisfaction of demand by the system. The diesel generator will be mobilized only in the event of a production deficit of the subsystem (PV, Wind, Tidal) and of the battery park to avoid consuming fuel and generating polluting emissions for the environment.

\section{Results and Discussions}

\subsection{Simulation Results}

HOMER modeled microgrids with different configurations to achieve the most cost effective and cost effective strategy, using component sizing inputs. Table 1 lists the optimization results categorized according to different configurations for the stand-alone system. Table 1 provides the results for the grid connected microgrid system. All results were ordered according to a decrease in TNPC.

After the various simulations HOMER identified 13 scenarios and configurations deemed to be the most profitable, from the parameters entered for the initial architecture as part of this study, the results were ordered in decreasing order of value of NPC and COE; these data are shown in Figure 19.

Configurations without photovoltaic components have high COEs and very high initial investment costs in the order of several million US \$, in our case study.

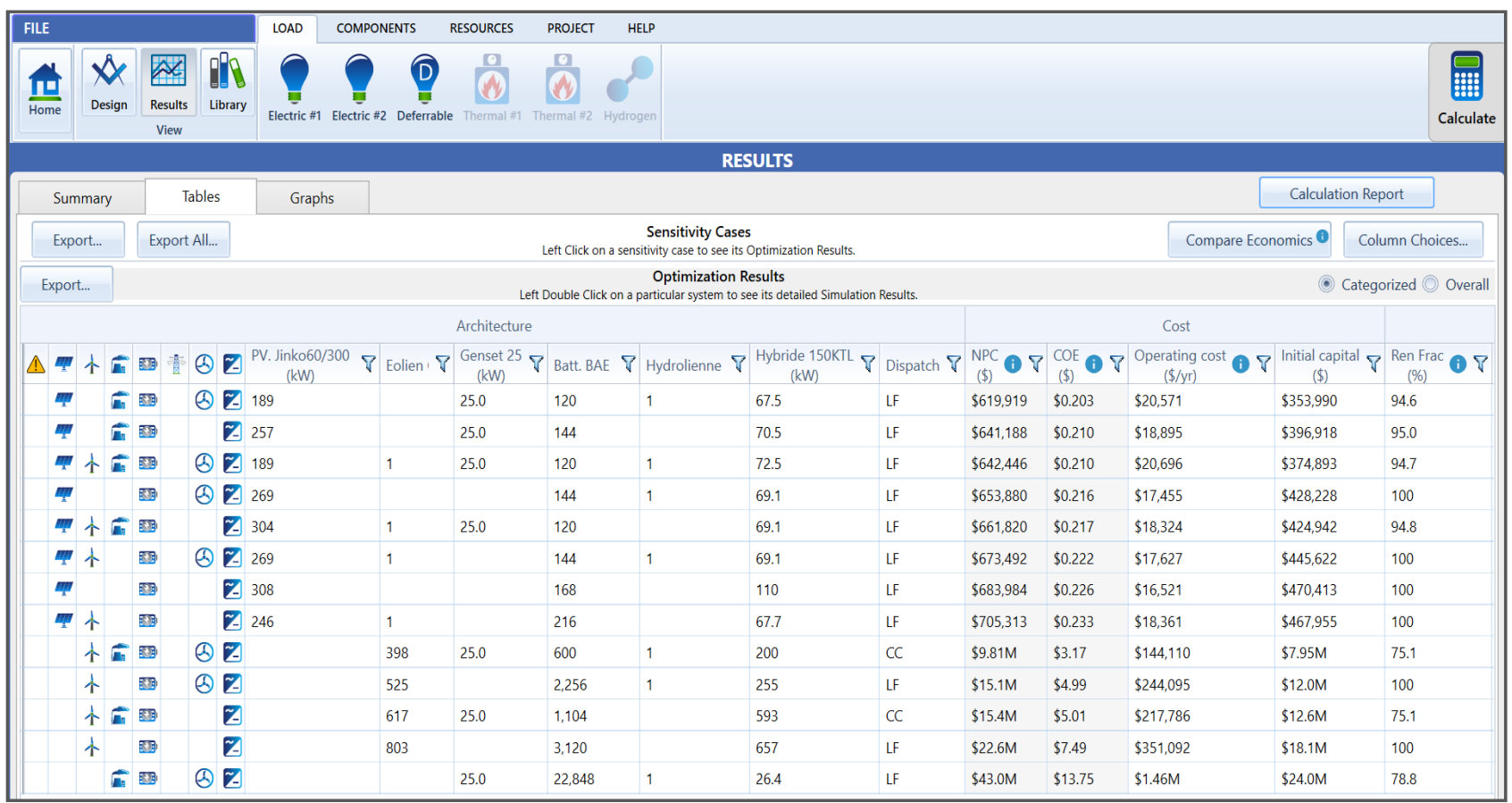




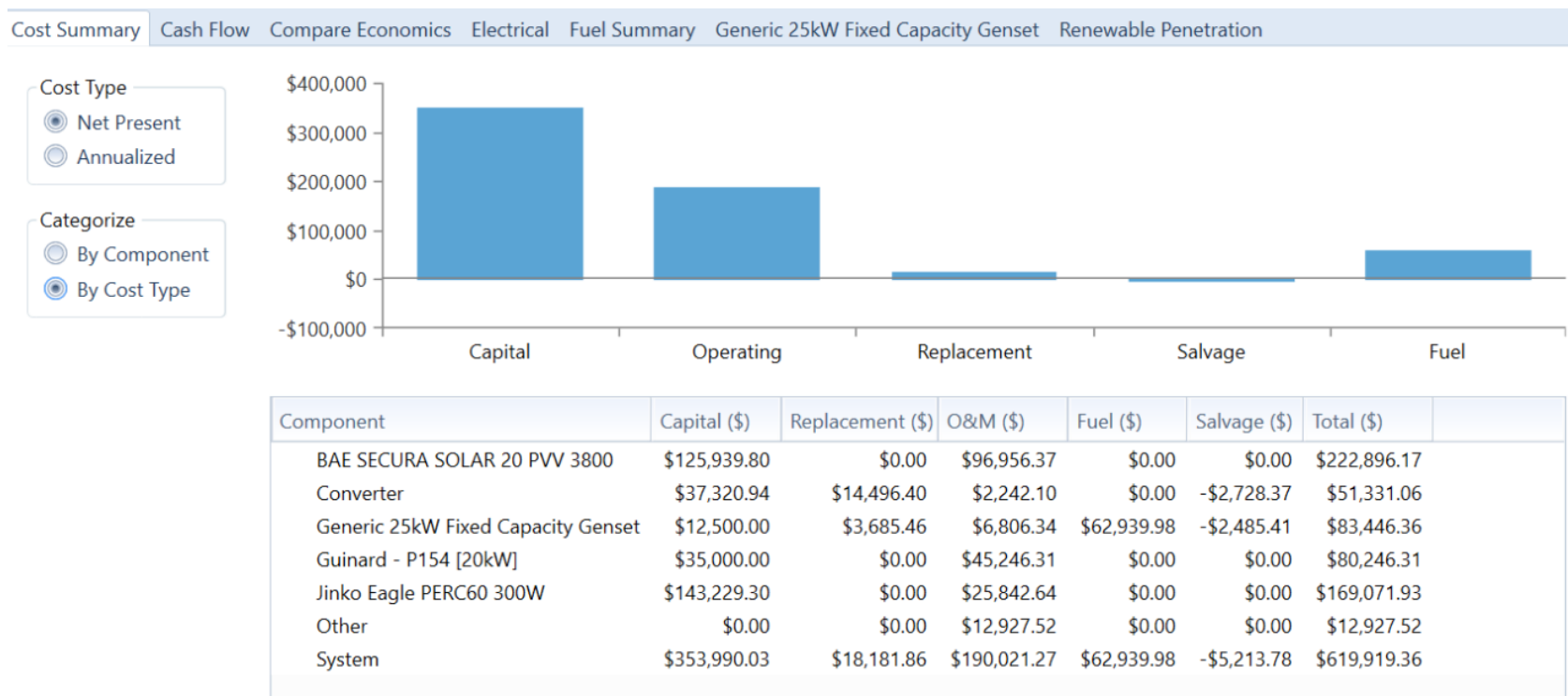

Figure 19. Optimization results classified according to different configurations for Elokato mini-grid.

$\mathrm{RE}$ power generators require high initial investments and relatively low operating costs. Hybrid systems with photovoltaic systems are of much greater interest than without a solar field.

The most optimal strategies with minimal TNPC between the stand-alone and grid-connected microgrid system were then compared and analyzed. The cash flows of stand-alone and grid-connected micro-grid systems are shown in Figure 20 and Figure 21, respectively.

The most important costs are generated by the battery park and then come the photovoltaic panels.

Figure 21 shows the chronological cash flows throughout the system lifecycle.

\subsection{Discussion of the Grid Extension distance at Equilibrium: Mini-Grid versus Interconnected Grid}

In electricity sector development strategy, a master plan dedicated to rural electrification has been drawn up by the Ministry of Energy.

The cost of the PDER (Rural Electrification Master Plan) is given in Table 2 for the 2015-2020 baseline scenario [2].

The Figure above shows that the cost of the breakeven point of extending the power grid compared to the two hybrid systems analyzed. For the hybrid $\mathrm{PV} /$ wind/diesel/hydropower system is profitable if the distance from the village to the transformer station is greater than $1.90 \mathrm{~km}$.

\section{Conclusions}

The approach of maximizing environmental, economic and technological benefits is the one favored in feasibility studies for decentralized mini-power grids.

In our case study, after the various simulations, HOMER identified 13 scenarios and configurations deemed to be the most profitable, from the parameters 


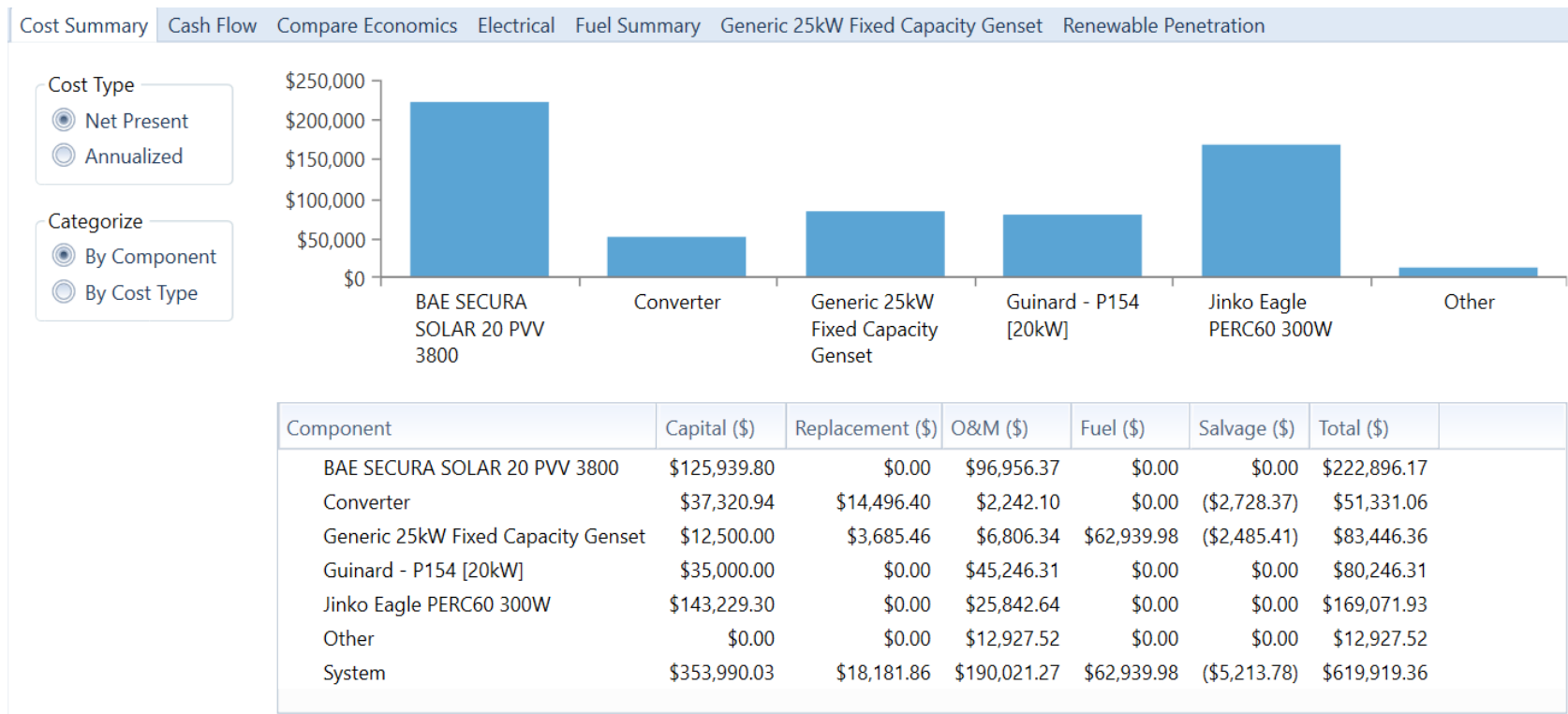

Figure 20. Summary of the costs of the case study.

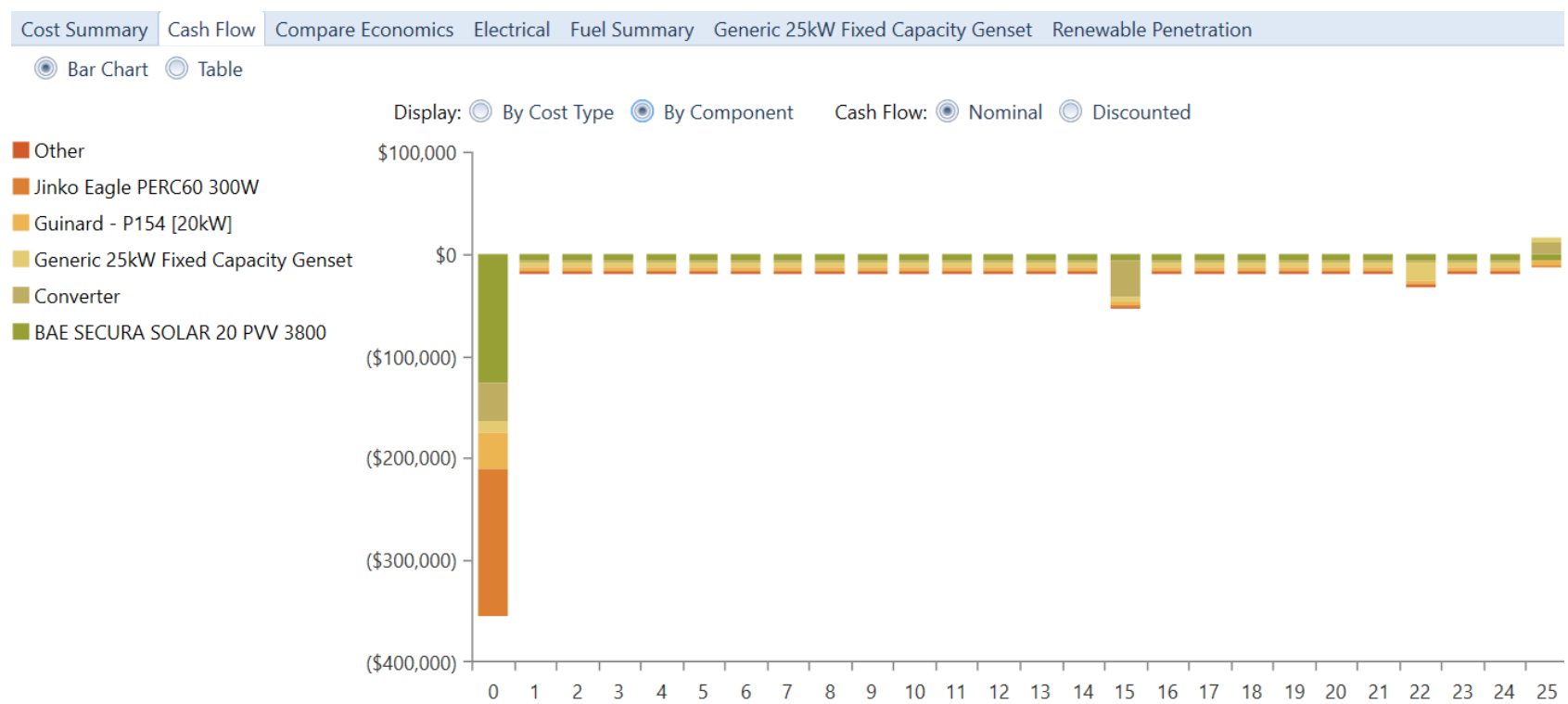

Figure 21. Cash flow.

Table 2. Total cost of the Rural Electrification Master Plan-RCI [2015-2020]

\section{Sources: CI-ENERGIES-Côte d Ivoire Electricity Sector Development Report-Registration Document-Page 52/103-February 2018 \\ Unité US \\ $\$(09 / 06 / 19)$}

Total Cost of Rural Electrification Master Plan [2015-2020]Billions XOF

578,4242

Principle results

Number of localities to be electrified

4968

Number of poles
200 


\section{Continued}

Population covered over the project period [2015-2020]

$5,385,325$

Length of MV Networks (km)

Investment (US \$)

$\$ 993,907,240$

1. MV networks (MV network)

$\$ 366,858,786$

2. HTA reinforcement (HTA network)

$\$ 207,633,083$

3. BTA Networks (Distribution Network)

4. Transformers (MV network)

5. Electric meters and connections (Distribution Network)

Indicators

Cost of the Distribution network/locality (US \$)

$\$ 84,389$

Cost of the HTA network/locality (M FCFA)

Total investment/location (US \$)

$\$ 200,062$

Total investment/capita (US \$)

and configurations without photovoltaic components have high COEs and very high initial investment costs in the order of several million US \$.

Renewable energy power generators require high initial investments and relatively low operating costs. The most important costs are generated by the battery park and then come the photovoltaic panels.

The hybrid $\mathrm{PV} /$ wind/diesel/hydropower system is profitable if the distance from the village to the transformer station is greater than $1.90 \mathrm{~km}$.

This paper studies the feasibility of mini-grids based on renewable energies in Côte d'Ivoire, and then also studies the technico-economic potential and the most suitable configurations in the various scenarios simulated with the software HOMER.

\section{Conflicts of Interest}

The authors declare no conflicts of interest regarding the publication of this paper.

\section{References}

[1] INED Biennial Study (2017, September). https://www.ined.fr/fichier/s_rubrique/26889/547.population.societes.septembre.20 17.tous.les.pays.du.monde.fr.pdf

[2] African Development Bank. https://www.afdb.org/fr/documents/document/the-new-deal-on-energy-for-africa-8 9193 
[3] 2017 ANARE CI Report, Table 6: Indicators Relating to Access to Electricity, Page 32.

[4] Registration Document February 2018, CI-ENERGIES, Page 54.

[5] Mamaghani, A.H., Escandon, S.A.A., Najafi, B., et al. (2016) Techno-Economic Feasibility of Photovoltaic, Wind, Diesel and Hybrid Electrification Systems for Off-Grid Rural Electrification in Colombia. Renew Energy, 97, 293-305. https://doi.org/10.1016/j.renene.2016.05.086

[6] Mazzola, S., Astolfi, M. and Macchi, E. (2016) The Potential Role of Solid Biomass for Rural Electrification: A Techno Economic Analysis for a Hybrid Microgrid in India. Applied Energy, 169, 370-383.

https://doi.org/10.1016/j.apenergy.2016.02.051

[7] Xu, Z., Nthontho, M. and Chowdhury, S. (2016) Strategies for Implementing Rural Electrification through a Microgrid Approach in the South African Context. International Journal of Electrical Power \& Energy Systems, 82, 452-465. https://doi.org/10.1016/j.ijepes.2016.03.037

[8] Akinyele, D.O. and Rayudu, R.K. (2016) Technical-Economic and Environmental Performance Analyzes of the Life Cycle of a Solar Photovoltaic Microgrid System for Developing Countries. Energy, 109, 160-179.

https://doi.org/10.1016/j.energy.2016.04.061

[9] Bekele, G. and Palm, B. (2010) Feasibility Study of a Solar-Wind Autonomous Hybrid Energy System for Application in Ethiopia. Applied Energy, 87, 487-495. https://doi.org/10.1016/j.apenergy.2009.06.006

[10] He, L., Zhang, S.Y., Chen, Y.Z., Ren, L.X. and Li, J. (2018) Techno-Economic Potential of a Renewable Energy-Based Microgrid System for a Sustainable Large-Scale Residential Community in Beijing, China. Renewable and Sustainable Energy Reviews, 93, 631-641. https://doi.org/10.1016/j.rser.2018.05.053

[11] Homer Pro. https://www.homerenergy.com/products/pro/docs/3.13/index.html 